through their member organisations. Respondents were asked to select a haemoglobin ( $\mathrm{Hb}$ ) trigger at which they would ordinarily transfuse red blood cells. Results were analysed using proportional odds models and robust standard errors were used to account for clustering.

Results The overall response rate was 48\% (815/1709). Transfusion triggers differed significantly between all six scenarios $(p<0.001)$. A Hb trigger $>9 \mathrm{~g} / \mathrm{dl}$ was chosen by only $13.3 \%$ of respondents to scenario 2 (young patient with features of shock). In comparison, a $\mathrm{Hb}$ trigger of $>9 \mathrm{~g} / \mathrm{dl}$ was chosen for $45.2 \%$ of respondents in scenario 4 representing an older patient with ischemic heart disease. $<4 \%$ of clinicians reported that they would ever transfuse at a $\mathrm{Hb}$ trigger of $>10 \mathrm{~g} / \mathrm{dl}$ in all scenarios. The selected $\mathrm{Hb}$ trigger differed between clinical specialities. Surgeons selected a lower $\mathrm{Hb}$ transfusion trigger than physicians across all 6 scenarios $(p<0.005)$, as did clinicians who had graduated within the past 5 years $(p<0.05$ compared to graduants $>5$ years). Only $70 \%$ of respondents reported familiarity with national guidelines for AUGIB. Most clinicians favoured a restrictive approach to transfusion, which is in part discordant with actual transfusion practice observed in the UK National Audit of AUGIB, where $15 \%$ of all early RBC transfusions were administered to patients with a $\mathrm{Hb}>10 \mathrm{~g} / \mathrm{dL}$ (38\% of whom were haemodynamically stable) and to $50 \%$ of admissions with a presenting $\mathrm{Hb} 8.1-10 \mathrm{~g} / \mathrm{dl}$ and haemodynamic stability.

Conclusion There is widespread variation in attitudes towards RBC transfusion for AUGIB. Both clinician and patient characteristics influence RBC transfusion decisions. Clinical studies are needed to evaluate the safety and efficacy of differing blood transfusion strategies in AUGIB.

Competing interests None.

\title{
REFERENCE
}

1. Hearnshaw SA, et al. Outcomes following early red blood cell transfusion in acute upper gastrointestinal bleeding. Aliment Pharmacol Ther 2010.

\section{PTU-087 خ RED CELL TRANSFUSION PRACTICE IN PATIENTS PRESENTING WITH ACUTE UPPER GASTROINTESTINAL BLEEDING- A SURVEY OF 815 CLINICIANS}

\author{
doi:10.1136/gut.2011.239301.215
}

V Jairath, ${ }^{{ }^{*}}$ B Kahan, ${ }^{2}$ R Logan, ${ }^{3}$ K Palmer, ${ }_{1}^{4}$ S Travis, ${ }^{5}$ M Murphy ${ }^{1}$ NHS Blood and Transplant, Oxford, UK; ${ }^{2}$ MRC Clinical Trials Unit, London, UK; ${ }^{3}$ Division of Epidemiology and Public Health, Nottingham, UK; ${ }^{4}$ Western General Infirmary, Edinburgh, ${ }^{5} \mathrm{John}$ Radcliffe Hospital, Oxford, UK

Introduction Acute Upper Gastrointestinal Bleeding (AUGIB) accounts for $14 \%$ of all red blood cell (RBC) transfusions in England. Studies of RBC transfusion practice in critical care and cardiac surgery have shown widespread practice variation. Since there are no such data in AUGIB and, as a consequence of recent evidence that early transfusion is associated with adverse outcomes in AUGIB, ${ }^{1}$ the current study was designed to assess attitudes towards $\mathrm{RBC}$ transfusion practice in patients presenting with AUGIB.

Methods A survey depicting six vignettes representing a range of clinical scenarios in AUGIB were piloted for content and emailed to practicing consultants and registrars in gastroenterology, acute medicine and upper gastrointestinal surgery 